\title{
Biogenic amines and their metabolites are differentially affected in the Mecp2-deficient mouse brain
}

\author{
Nicolas Panayotis ${ }^{1,2^{*}}$, Adeline Ghata ${ }^{1,2}$, Laurent Villard ${ }^{1,2}$ and Jean-Christophe Roux ${ }^{1,2}$
}

\begin{abstract}
Background: Rett syndrome (RT, MIM \#312750) is a severe neurological disorder caused by mutations in the Xlinked methyl-CpG binding protein 2 (MECP2) gene. Female patients are affected with an incidence of 1/15000 live births and develop normally from birth to 6-18 months of age before the onset of deficits in autonomic, cognitive, motor functions (stereotypic hand movements, impaired locomotion) and autistic features. Studies on Mecp2 mouse models, and specifically null mice, revealed morphological and functional alterations of neurons. Several functions that are regulated by bioaminergic nuclei or peripheral ganglia are impaired in the absence of Mecp2.

Results: Using high performance liquid chromatography, combined with electrochemical detection (HPLC/EC) we found that Mecp ${ }^{-1 y}$ mice exhibit an alteration of DA metabolism in the ponto-bulbar region at 5 weeks followed by a more global alteration of monoamines when the disease progresses ( 8 weeks). Hypothalamic measurements suggest biphasic disturbances of norepinephrine and serotonin at pathology onset ( 5 weeks) that were found stabilized later on (8 weeks). Interestingly, the postnatal nigrostriatal dopaminergic deficit identified previously does not parallel the reduction of the other neurotransmitters investigated. Finally, dosage in cortical samples do not suggest modification in the monoaminergic content respectively at 5 and 8 weeks of age.

Conclusions: We have identified that the level of catecholamines and serotonin is differentially affected in Mecp $2^{-/ y}$ brain areas in a time-dependent fashion.
\end{abstract}

\section{Background}

Rett syndrome (RTT, MIM \#312750) is a severe neurological disorder caused by mutations in the $\mathrm{X}$-linked methyl-CpG binding protein 2 (MECP2) gene [1]. Female patients are affected with an incidence of $1 / 15000$ live births $[2,3]$ and develop normally from birth to 6-18 months of age before the onset of deficits in autonomic, cognitive, motor functions and autistic features $[4,5]$. Several studies shed light on the involvement of catecholaminergic and serotonergic disturbances as a major contributor of the disease in RTT patients and Mecp 2 mouse models. Neurochemical analyses of biogenic amines in Mecp2-null male ( $\left.M e c p 2^{-/ y}\right)$ were previously performed on whole brain homogenates showing that the concentration of dopamine (DA), norepinephrine (NE)

\footnotetext{
* Correspondence: nicolas.panayotis@univmed.fr

'INSERM UMR_S 910, Unité de Génétique Médicale et Génomique

Fonctionnelle, Equipe de Neurogénétique Humaine, France

Full list of author information is available at the end of the article
}

and serotonin (5-HT) was reduced after birth [6,7]. Moreover, the absence of Mecp2 impairs several functions that are regulated by bioaminergic nuclei or peripheral ganglia where such neurochemical deficits occur [8-12]. However, these studies are discordant for several parameters. Here, we evaluated the level of DA, NE and 5-HT and their catabolites homovanillic Acid (HVA), dihydroxyphenylacetic acid (DOPAC) and 5-hydroxyindoleacetic acid (5-HIAA), using high performance liquid chromatography, combined with electrochemical detection (HPLC/EC). We performed our analyses on micropunched brain samples from the cortex, caudateputamen, hypothalamus, midbrain (Substantia Nigra + Ventral Tegmental Area) and the hindbrain (Brainstem + Pons) (Figure 1) of $\mathrm{Mecp}^{-/ y}$ mice and their respective age-matched wild-type (WT) littermates from postnatal day 35 (P35, disease onset) and 55 (P55, severe phenotype).

\section{Ciomed Central}




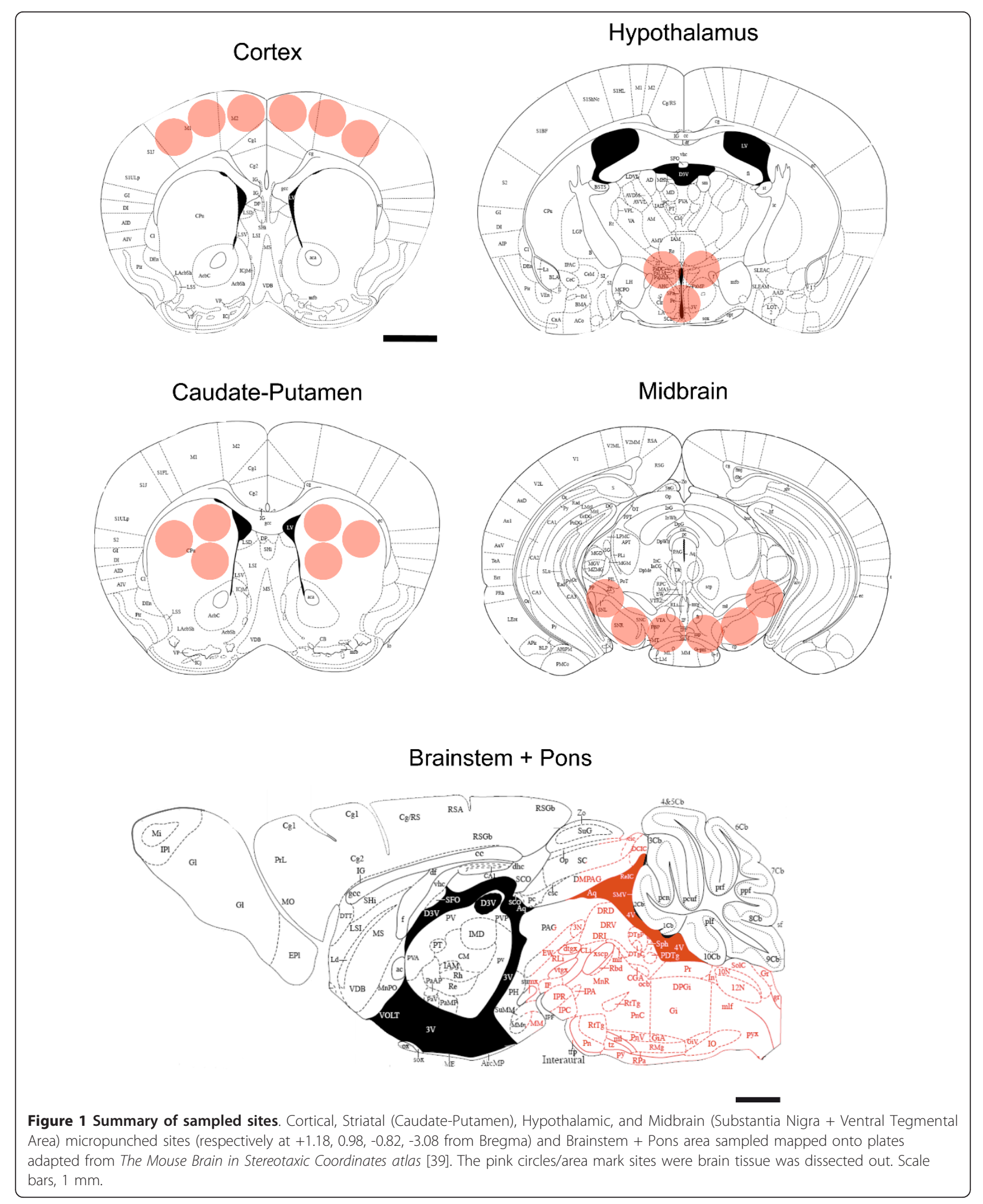




\section{Results}

Neither catecholamines nor serotonin levels are affected in the cortex of Mecp2 $2^{-/ y}$

Neurochemical analysis performed in the cortex showed no perturbation at P35 for DA, NE and 5-HT levels in $M e c p 2^{-/ y}$ compared to their WT littermates ( $\left.\mathrm{p}>0.05\right)$. No significant alterations were observed at P55 for DA, $\mathrm{NE}$ and 5-HT ( $\mathrm{p}>0.05$ ). DA measurements in the cortex display great variability possibly masking differences between the two genotypes (Figure 2A). Dopaminergic catabolites HVA and DOPAC were unaffected at P35 and P55 ( $\mathrm{p}>0.05$ ). The serotonin metabolite 5-HIAA is not different between $M e c p 2^{-/ y}$ and WT at P35 and P55 $(\mathrm{p}>0.05)$ (Figure 3A). Altogether, these results argue for a preserved biogenic amines metabolism in the cortex of Mecp2-null mice.

The alteration of norepinephrine and serotonin levels in the hypothalamus of $M e c p 2^{-/ y}$ is postnatal and biphasic Next, we measured biogenic amines concentrations in the hypothalamus. It was previously reported that a targeted deletion of Mecp2 in Single-minded 1 gene (Sim1)-expressing neurons (located in several hypothalamic nuclei) results in a body of behavioural deficits ranging from feeding disturbances to stress [13]. Increased levels of corticosterone and leptin together with Brain-derived neurotrophic factor (Bdnf) deficits are possible contributors for this phenotype in this mouse. Since catecholamines play a role in hypothalamic nuclei neurotransmission and interplays with leptin and Bdnf [14-17] we wanted to assess deficits in bioamines and their degradation products. Deficits were observed at P35 for NE and 5-HT ( $<0.05)$. No alteration of DA levels was noticed at this age $(\mathrm{p}>0.05)$. However, the NE and 5-HT decrease identified at P35 was no longer present at P55 and DA levels were normal at P55 (p > 0.05) (Figure 2B). All the tested catabolites were found to be normal in the hypothalamus of $M e c p 2^{-/ y}$ compared to WT at P35 and P55 (Figure 3B).

\section{Bioaminergic disturbances are global and progressive in pontic and brainstem area of Mecp $^{-/ y}$}

DA, NE and 5-HT contents were evaluated by HPLC using pons and brainstem samples of $M e c p 2^{-/ y}$ animals and WT animals at P35 and P55 (Figure 2C). DA is reduced both at P35 and at P55 (p < 0.05). NE levels are normal at P35 ( $>$ > 0.05) but are clearly reduced at P55 $(\mathrm{p}<0.05)$. For serotonin, we found the same pattern of alteration, with no decrease at P35 (p > 0.05) but a decrease at P55 ( $<<0.05)$. Altogether, our results suggest that $M e c p 2^{-/ y}$ mice have lower levels of biogenic amines than their WT littermates.

We respectively assessed the level of HVA, DOPAC and 5-HIAA in these samples (Figure 3C). At P35, the only catabolite affected is HVA $(\mathrm{p}<0.05)$ whereas
DOPAC and 5-HIAA are normal ( $\mathrm{p}>0.05$ ). At P55, the levels of HVA, DOPAC and 5-HIAA were all reduced in Mecp $^{-/ y}$ compared to WT samples $(\mathrm{p}<0.05)$.

\section{$M_{\text {ecp }} 2^{-/ y}$ nigrostriatal dopaminergic deficits do not parallel noradrenergic or serotonergic ones}

We previously reported a postnatal reduction of DA and HVA but not DOPAC in the caudate-putamen of $\mathrm{Mecp}^{-/ \mathrm{y}}$ at P35 and P55 [12] (illustrated on Figure 2D and Figure 3D). Here, we observed that at P35, neither NE nor 5-HT contents were affected $(p>0.05)$. This observation stands true for these neurotransmitters at P55 ( $\mathrm{p}>0.05)$. We measured the level of 5-HIAA and found no alteration at P35 ( $p>0.05)$, and P55 ( $p>0.05)$. These results indicate that the noradrenergic and serotonergic neurotransmitters are unaffected in the caudateputamen of $M e c p 2^{-/ y}$ compared to their WT littermates at all ages investigated (Figure 2D and Figure 3D).

Our previous work failed to detect changes in the level of DA and DOPAC in the Mecp $2^{-/ y}$ midbrain at both P35 and P55. However, we observed a clear reduction of HVA in these dopaminergic neurons at the most advanced age [12] (illustrated on Figure 2E and Figure $3 \mathrm{E})$. We extended our analysis to NE, 5HT and 5-HIAA at both ages. Our results show that NE is not altered at P35 in Mecp2-deficient midbrain ( $\mathrm{p}>0.05$ ). 5-HT levels are also preserved compared to WT level at the same age $(\mathrm{p}>0.05)$. Samples obtained from symptomatic mice (P55) do no exhibit any modification of the substrate levels compared to age-matched WT $(\mathrm{p}>0.05)$ (Figure 2E). 5-HIAA values are normal at P35 (p > 0.05) and at P55 ( $\mathrm{p}>0.05)$ in $\mathrm{Mecp}^{-/ \mathrm{y}}$ samples compared to age-matched WT (Figure 3E).

\section{Discussion}

$M e c p 2^{-/ y}$ cortical neurons exhibit several alterations, ranging from reduced activity to abnormal dendritic spine morphology $[18,19]$. These defects are influenced by Bdnf dosage [20]. Bdnf plays a key role in neuronal survival, differentiation and synaptic plasticity [21]. Bdnf metabolism was shown to be involved in the development and function of catecholaminergic neurons, affected in $\mathrm{Mecp}^{-/ y}$ [22-25]. Recently, several studies identified NE reductions in the piriform cortex of Mecp2-null mouse at P35 [9] and in the prefrontal and motor cortex at both 3 (P21) and 8 (P56) weeks of age [11]. We were not able to reproduce these findings. One possible explanation for this divergence could be differences in the sampling procedure. We performed micropunches of the motor cortex. Different cortical territories receive monoaminergic inputs from different nuclei, some areas being less densely innervated than others [26]. Serotonergic dosage in $M e c p 2^{-/ y}$ brains were also reported and discrepancies are existing. Isoda and 


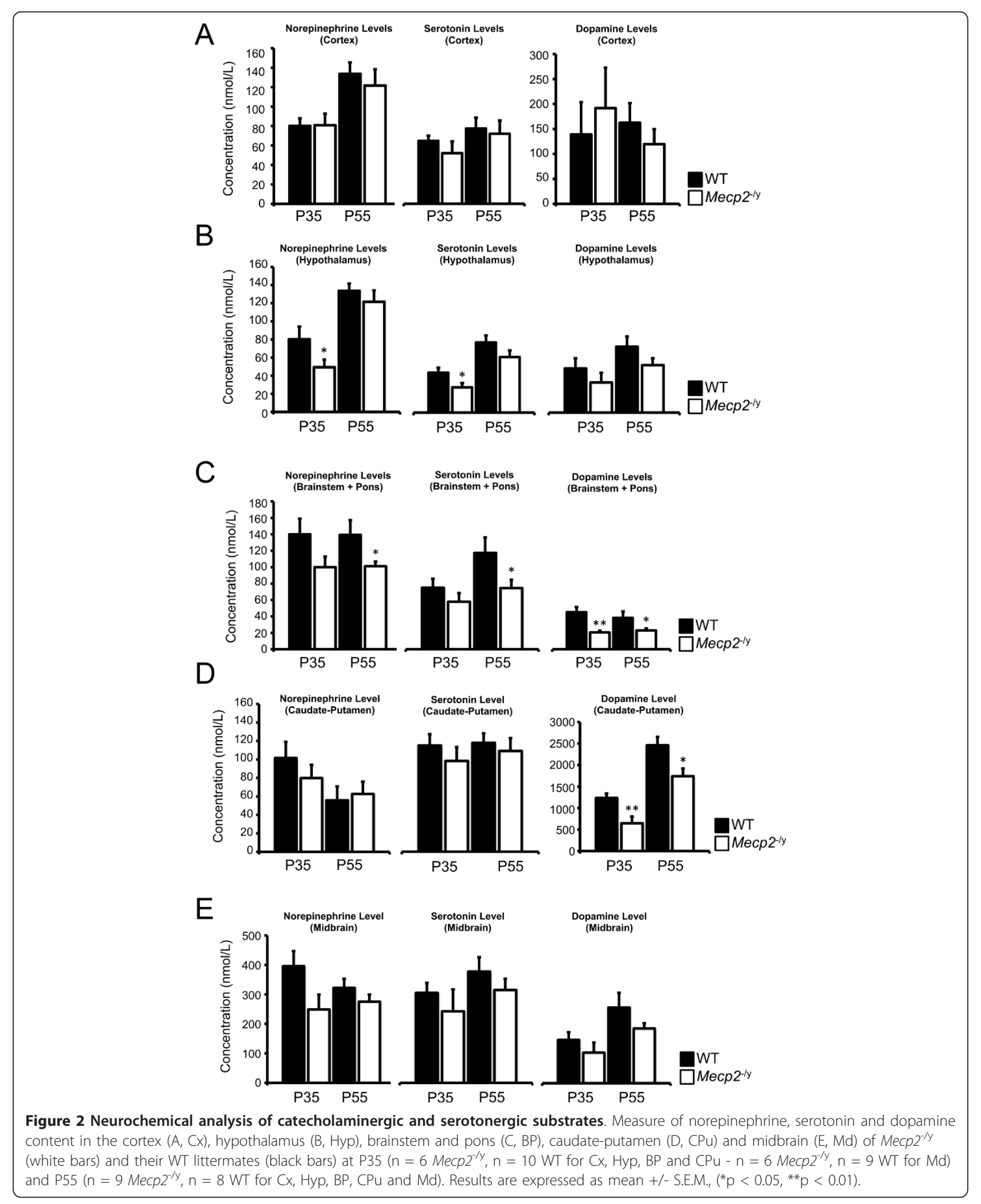



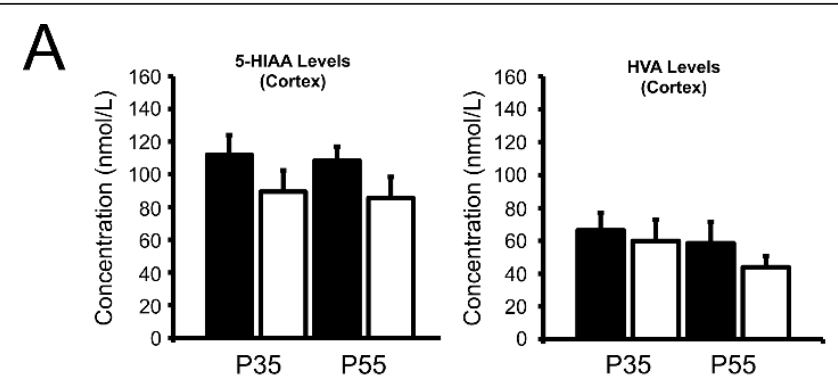

DOPAC Levels (Cortex)

B
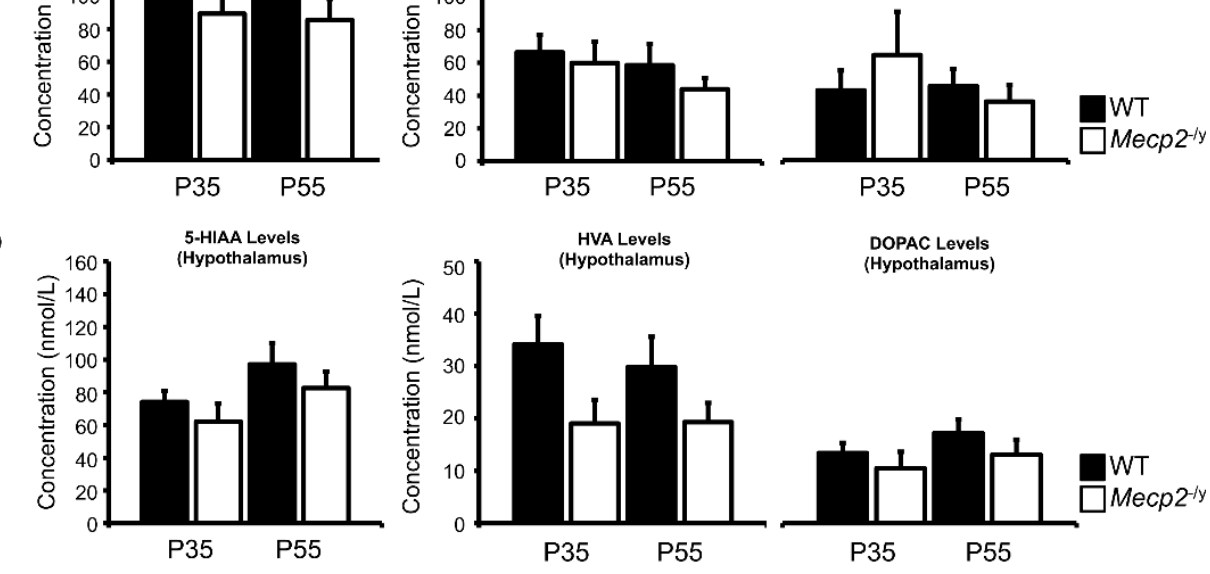

DOPAC Levels
(Hypothalamus)

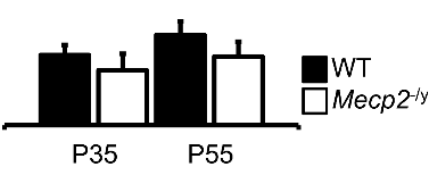

$\mathcal{C}$
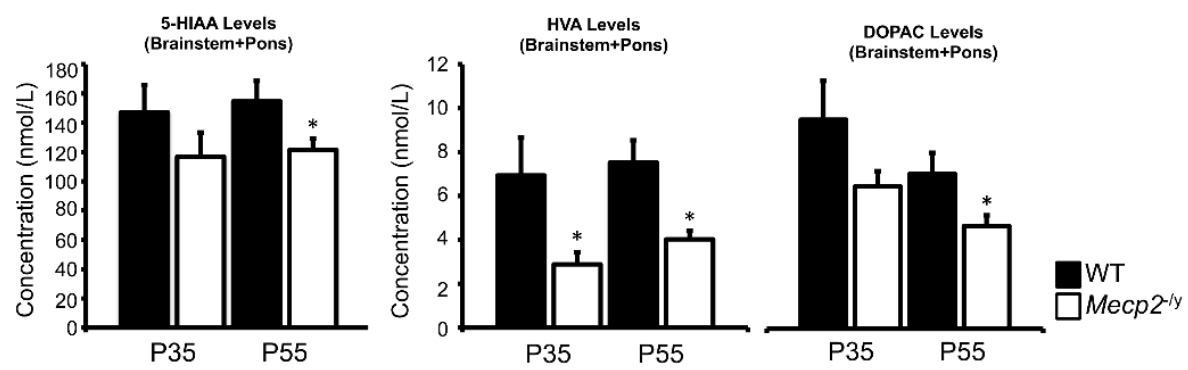

$\mathrm{D}$
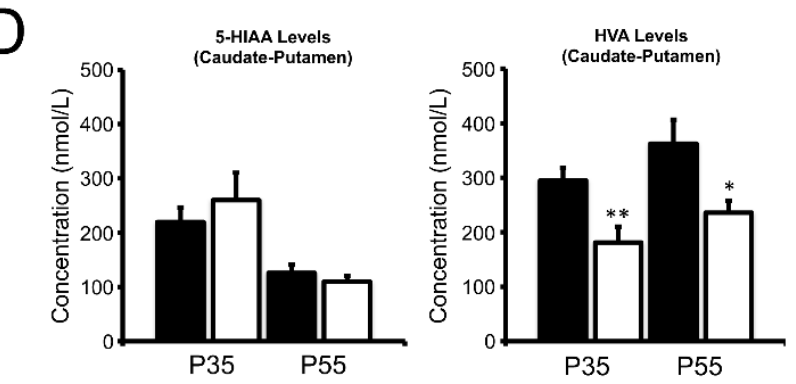

DOPAC Levels (Caudate-
Putamen)
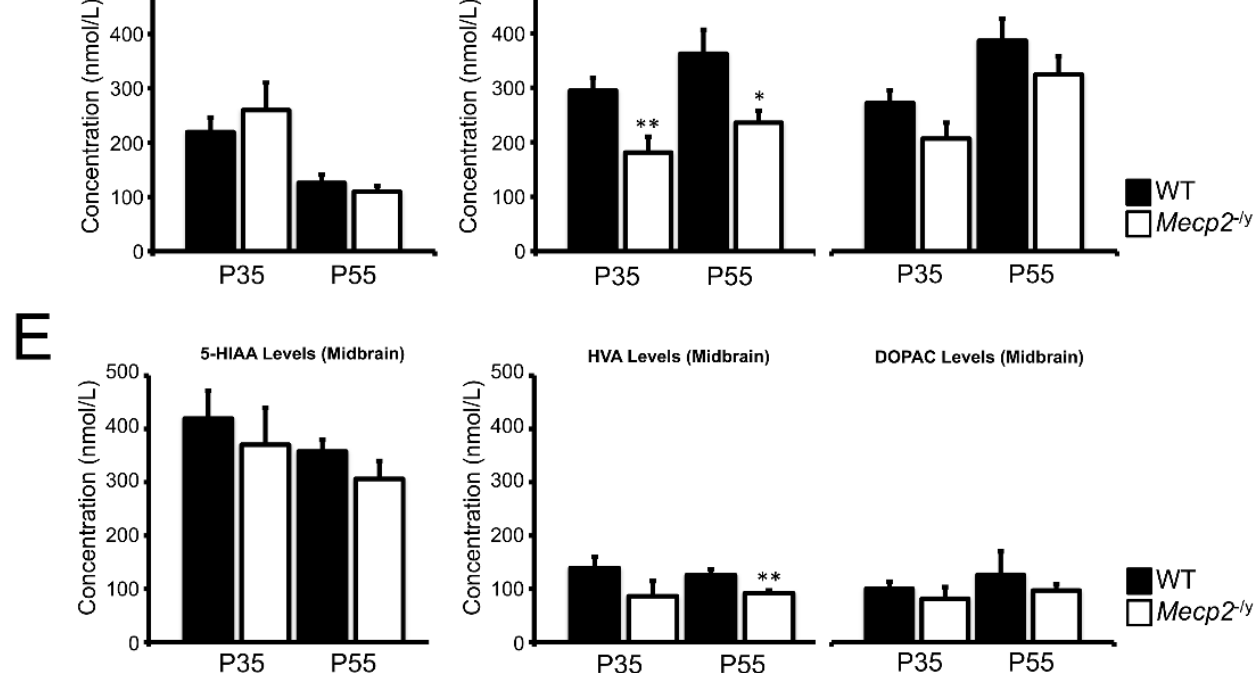

DOPAC Levels (Midbrain)

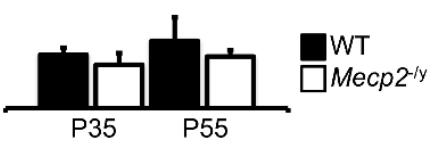

Figure 3 Neurochemical analysis of dopaminergic and serotonergic catabolites. Measure of homovanillic acid (HVA), dihydroxyphenylacetic acid (DOPAC) and 5-hydroxyindoleacetic acid (5-HIAA) content in the cortex (A, Cx), hypothalamus (B, Hyp), brainstem and pons (C, BP), caudateputamen ( $\mathrm{D}, \mathrm{CPu})$ and midbrain ( $\mathrm{E}, \mathrm{Md})$ of $\mathrm{Mecp}^{-/ y}$ (white bars) and their WT littermates (black bars) at P35 ( $\mathrm{n}=6 \mathrm{Mecp2^{-1/ }}, \mathrm{n}=10 \mathrm{WT}$ for $\mathrm{Cx}$, Hyp, BP and CPu $-n=6 \mathrm{Mecp}^{-1 / y}, n=9 \mathrm{WT}$ for Md) and P55 ( $n=9 \mathrm{Mecp2}^{-1 /}, \mathrm{n}=8 \mathrm{WT}$ for Cx, Hyp, BP, CPu and Md). Results are expressed as mean + - S.E.M., $\left({ }^{*} p<0.05,{ }^{* *} p<0.01\right)$. 
collaborators did not to identify any modifications of 5HT and its main catabolite 5-HIAA in the prefrontal cortex from P14 to P56 [10]. However, another laboratory argued for a reduction in the same structure of 5HT only, at 3 and 8 weeks of age [11]. As Isoda and coauthors measured, we did not found significant reductions of 5-HT or 5-HIAA. Another group reported a 5HT deficit in whole brain extracts in the same developmental window [7]. Unfortunately, samples used in this study came from pooled 6 to 8 weeks $M e c p 2^{-/ y}$ animals, two ages that are know to be phenotypically different according to the postnatal development of the $M e c p 2^{-/ y}$ mouse pathology [27]. These results thus combine 5-HT contents from both mildly and severely affected animals.

It is generally believed that catecholamines play a role in hypothalamic nuclei neurotransmission and that their release is modulated by several factors including Bdnf and leptin [17]. Here, we report a postnatal alteration of hypothalamic NE and 5-HT contents that follows a biphasic scheme. These biogenic amines were found significantly decreased at P35 in $\mathrm{Mecp}^{-/ \mathrm{y}}$ animals whereas their levels are not significantly different from WT at P55. A recent study showed that specific deletion of Mecp2 in Sim1-positive neurons in the paraventricular nucleus (PVN) of the hypothalamus results in higher serum level of leptin [13]. Since leptin was proposed to lower NE-dependant oxytocin release in the PVN [17] and to reduce firing of serotonergic neurons [28] it was tempting to assess the level of bioamines in this brain area. Our results at P35 could reflect a leptin-dependant bioaminergic reduction. However, Fyffe and coauthors did not identify alterations at 6 weeks (P42) but noticed a significant increase 42 weeks. It is important to stress that Mecp2-deletion is not restricted to hypothalamic neurons in the model we used. Moreover, mice used in one study were of mixed 129/FVB genetic background [13] while we used C57Bl6 Mecp2-/y mice [29].

In agreement with Taneja and co-workers [9], we found a reduction of DA and HVA in our hindbrain samples containing both the brainstem and the pons at P35. However, we did not found DOPAC reduction. Taneja et al. used a different $M e c p 2^{-/ y}$ strain (i.e. generated by Jaenisch laboratory; [30]). It would be interesting to investigate possible difference in the activity/modulation of DA degradation enzymes in these two models. In the Bird mouse [29] no difference was found in monoamine oxydase (MAO-A and MAO-B) activity in the cortex [11]. It remains to be determined if MAO and/or catechol-O-methyl transferase (COMT) levels are impaired elsewhere. Interestingly, the caudal structures are the most affected with dopaminergic disturbances at P35 when the Mecp2 animals display a mild phenotype, and a global monoaminergic deficit at P55 affecting DA, NE, 5-HT and their degradation products.
This is in good agreement with several studies arguing for a brainstem and pontic basis for the Mecp $2^{-/ y}$ phenotype and RTT symptoms in humans [31,32]. The observed increase in the serotonergic ratio (Table 1) at P55 in the pons and brainstem supports a possible alteration of 5-HT projections innervating this structure and modulating the autonomic functions altered in the absence of Mecp2 [33].

$M e c p 2^{-/ y}$ mice display a progressive and postnatal alteration in their motor behavior $[11,34]$. Interestingly, mice with a targeted deletion of Mecp 2 in Th-expressing neurons show a deficit in motricity among other dysregulations [7]. We recently described in mice harboring a constitutive deletion of $M e c p 2$ progressive alterations of

Table 1 Metabolite/5-HT and metabolite/DA ratios in the cortex, hypothalamus, caudate-putamen, midbrain and brainstem/pons of WT and Mecp2 $2^{-/ y}$

\begin{tabular}{|c|c|c|c|}
\hline Brain Area & Group & $\begin{array}{l}\text { 5HIAA/ } 5 \mathrm{HT} \\
\text { ratio }\end{array}$ & $\begin{array}{c}(\mathrm{HVA}+\underset{\text { ratio }}{\mathrm{DOPAC}) / \mathrm{DA}} \\
\text { ration }\end{array}$ \\
\hline \multirow[t]{4}{*}{ Cortex } & P35 Wt & $1.68(+/-0.14)$ & $1.71(+/-0.42)$ \\
\hline & P35 Ko & $1.88(+/-0.29)$ & $1.33(+/-0.43)$ \\
\hline & P55 Wt & $1.50(+/-0.17)$ & $0.75(+/-0.10)$ \\
\hline & P55 Ko & $1.47(+/-0.29)$ & $0.77(+/-0.12)$ \\
\hline \multirow[t]{4}{*}{ Hypothalamus } & P35 Wt & $1.92(+/-0.26)$ & $0.85(+/-0.06)$ \\
\hline & P35 Ko & $\begin{array}{c}2.61(+/-0.37) \\
*\end{array}$ & $0.94(+/-0.12)$ \\
\hline & P55 Wt & $1.37(+/-0.12)$ & $0.73(+/-0.15)$ \\
\hline & P55 Ko & $1.54(+/-0.22)$ & $0.62(+/-0.09)$ \\
\hline \multirow[t]{4}{*}{ CaudatePutamen } & P35 Wt & $1.91(+/-0.11)$ & $0.47(+/-0.03)$ \\
\hline & P35 Ko & $\begin{array}{c}2.64(+/-0.22) \\
* *\end{array}$ & $0.62(+/-0.05)$ \\
\hline & P55 Wt & $1.06(+/-0.13)$ & $0.30(+/-0.02)$ \\
\hline & P55 Ko & $1.02(+/-0.08)$ & $0.33(+/-0.02)$ \\
\hline \multirow[t]{4}{*}{ Midbrain } & P35 Wt & $1.51(+/-0.23)$ & $1.66(+/-0.14)$ \\
\hline & P35 Ko & $1.79(+/-0.27)$ & $1.64(+/-0.09)$ \\
\hline & P55 Wt & $1.06(+/-0.13)$ & $1.07(+/-0.13)$ \\
\hline & P55 Ko & $1.02(+/-0.08)$ & $0.99(+/-0.04)$ \\
\hline \multirow{4}{*}{$\begin{array}{l}\text { Brainstem + } \\
\text { Pons }\end{array}$} & P35 Wt & $2.27(+/-0.39)$ & $0.36(+/-0.03)$ \\
\hline & P35 Ko & $2.18(+/-0.31)$ & $0.43(+/-0.09)$ \\
\hline & P55 Wt & $1.17(+/-0.06)$ & $0.44(+/-0.06)$ \\
\hline & P55 Ko & $2.00(+/-0.51)$ & $0.39(+/-0.02)$ \\
\hline
\end{tabular}

Shown are mean values +/- S.E.M. for the ratios of dopaminergic metabolites HVA + DOPAC/DA and serotonergic metabolite 5-HIAA/5-HT in the cortex (CX), the hypothalamus (Hyp), the caudate-putamen (CPu), midbrain (Md) and brainstem + pons (BP) of Mecp2 ${ }^{-/ y}$ and their WT littermates at P35 and P55. Dopamine turnover was unafected in the $\mathrm{Cx}, \mathrm{Hyp}, \mathrm{CPu}, \mathrm{Md}$ and $\mathrm{BP}$ at both P35 and P55 in Mecp2 ${ }^{-1 y}$ compared to their age-matched WT littermates. Serotonergic turnover was not modified in $\mathrm{Cx}$ and $\mathrm{Md}$ at any age investigated. However, Hyp and CPu dosage revealed a significant increase of 5-HIAA/5-HT ratio at P35 but not P55. In turn, values from the BP indicate a clear increase in the serotonergic turnover in $M e c p 2^{-/ y}$ when they exhibit the most severe phenotype (P55). ( ${ }^{*} p<0.05,{ }^{* *} p<0.01$ ). 
the SNpc and the nigrostriatal dopaminergic pathway, a key component of the brain motor circuitry [12]. Moreover, some of the behaviors impaired were ameliorated by L-Dopa, arguing for a strong, although clearly nonunique, involvement of the DA disturbances in $M e c p 2^{-/ y}$ motor phenotype. In complement to this previous study, we here pursued our neurochemical investigations for $\mathrm{NE}$ and 5-HT in the SNpc and its striatal target. NE, provided from the Locus Coeruleus, A1 and A2 (from brainstem) is implicated in several brain functions and its action on midbrain DA neurons was shown to modulate motivational behaviors $[35,36]$. The absence of NE and 5-HT disturbances in the midbrain and the caudate-putamen confirm previous findings $[10,11]$.

The consequence of Mecp2-deficiency on the integrity of dopaminergic and serotonergic nuclei could be indexed on the HVA + DOPAC/DA and 5-HIAA/5-HT ratios respectively since a toxic alteration of dopaminergic and serotonergic systems induces counteradaptative processes that impact on this values $[37,38]$. The calculated ratios are reported in Table 1 . Results suggest dopamine turnover was left unaffected in all the structures investigated at both P35 and P55 in $\mathrm{Mecp}^{-/ \mathrm{y}}$ compared to their WT littermates. Conversely, hypothalamus and caudate-putamen dosage revealed a significant increase of 5-HIAA/5-HT ratio at P35 but not P55. Values from the pons and brainstem indicate a clear increase in the serotonergic turnover in $M e c p 2^{-/ y}$ at P55. However, this index was not modified in the cortex and the midbrain at P35 and P55. Alteration of the serotonergic innervation lead to an increase in the turnover [37]. Interestingly, a reduction in 5-HT immunoreactive fibers was reported in the hippocampus of $M e c p 2^{-/ y}$ animals [10]. It remains to be elucidated if such phenomenon contribute to serotonergic deficits described here.

\section{Conclusions}

Our results indicate that the level of catecholamines and serotonin is differentially affected in $M e c p 2^{-/ y}$ brain areas in a time-dependent fashion (Figure 4). Considering behavioral and physiological function altered in the context of Mecp2-deficiency and the positive impact of drugs targeting this system, monoamine neurochemical dosage could help identifying therapeutics resetting central bioaminergic deficits in different brain areas of the Mecp2-deficient mouse.

\section{Methods}

\section{Animals}

Experiments were performed on the B6.129P2(c)Mecp $2^{\text {tm1-1Bird }}$ mouse model for RTT [29]. The mice were obtained from the Jackson Laboratories and maintained on a $\mathrm{C} 57 \mathrm{Bl} / 6$ background. The experimental procedures were carried out in keeping with the European guidelines for the care and use of laboratory animals (Council Directive 86/609/EEC). Both pre-symptomatic and symptomatic mice were analyzed at different developmental stages. A total number of $15 \mathrm{Mecp}^{-/ \mathrm{y}}$ and 18 WT male mice were used in the study. The Mecp $2^{-/ y}$ (null male) and WT (wild-type male) mice were studied at postnatal days 35 (P35; $\left.\mathrm{n}=10 \mathrm{WT} ; \mathrm{n}=6 \mathrm{Mecp}^{-/ \mathrm{y}}\right)$ and 55 (P55; $\left.\mathrm{n}=8 \mathrm{WT} ; \mathrm{n}=9 \mathrm{Mecp}^{-/ \mathrm{y}}\right)$ for neurochemical analysis. Mecp2-deficient mice were compared to their respective WT littermates of the same gender. Breeding and genotyping were performed as previously described [23].

\section{Tissue sampling}

P35 ( $\mathrm{n}=10 \mathrm{WT} ; \mathrm{n}=6 \mathrm{Mecp}^{-/ \mathrm{y}}$ ) and P55 (n = $8 \mathrm{WT}$; $\mathrm{n}$ $\left.=9 \mathrm{Mecp}^{-/ \mathrm{y}}\right)$ mice were killed by cervical dislocation, and their brains were dissected out within the first 2 min post-mortem. The motor cortex, Caudate-Putamen, Midbrain area (Substantia Nigra + Ventral Tegmental Area) were microdissected using a punching needle $(0.5$ $\mathrm{mm} \varnothing$ ) and kept at $-80^{\circ} \mathrm{C}$ until biochemical analysis. The region containing both the Pons and the Brainstem was dissected under a binocular microscope (Figure 1). Briefly, brain area dissection was performed on cryostat brain sections with the help of a $5 \times$ magnifying lens, following their stereotaxic coordinates $[39,40]$.

\section{Chemicals}

Norepinephrine, DHBA, dopamine, DOPAC, HVA, serotonin (5-hydroxytryptamine, 5-HT), 5-hydroxyindole-3acetic acid (5-HIAA), 1-octanesulfonic acid (OSA), triethylamine and ethylene-diamine-tetra-acetic acid (EDTA) disodium salt were purchased from Sigma, sodium dihydrogen phosphate and citric acid from Merck and methanol from Prolabo. Ultrapure water was obtained with a Milli-Q system (Millipore, Bedford, MA, USA). Standard solutions of each monoamine or metabolite were stored at $-20^{\circ} \mathrm{C}$ at $1 \mathrm{mmol} / \mathrm{L}$ as aliquots.

\section{HPLC}

The HPLC system was composed of a Hitachi L-7000 series equipped with a degasser, a L-7100 pump, an L7200 autosampler thermostated at $10^{\circ} \mathrm{C}$ and a Decade Intro electrochemical detector fitted with a $3 \mathrm{~mm}$ glass carbon working electrode, an $\mathrm{Ag} / \mathrm{AgCl}$ reference electrode and a $25 \mu \mathrm{m}$ spacer (Antec, Leyden, The Netherlands). Separations were performed using a $250 \mathrm{~mm} \times$ $4.6 \mathrm{~mm}$ i.d. C18 $5 \mu \mathrm{m}$ Beckman Ultrasphere column equipped with two Phenomenex C18 filters in a security guard system. The mobile phase was pumped at a microflow rate of $0.8 \mathrm{~mL} / \mathrm{min}$ and composed of 0.7 $\mathrm{mol} / \mathrm{L}$ sodium phosphate, $0.1 \mathrm{mmol} / \mathrm{L}$ EDTA, $1.1 \mathrm{mmol} /$ L OSA, $3.1 \mathrm{mmol} / \mathrm{L}$ triethylamine, $14 \%$ methanol, $\mathrm{pH}$ adjusted to 3.12 with $1 \mathrm{mmol} / \mathrm{L}$ citric acid, it was 


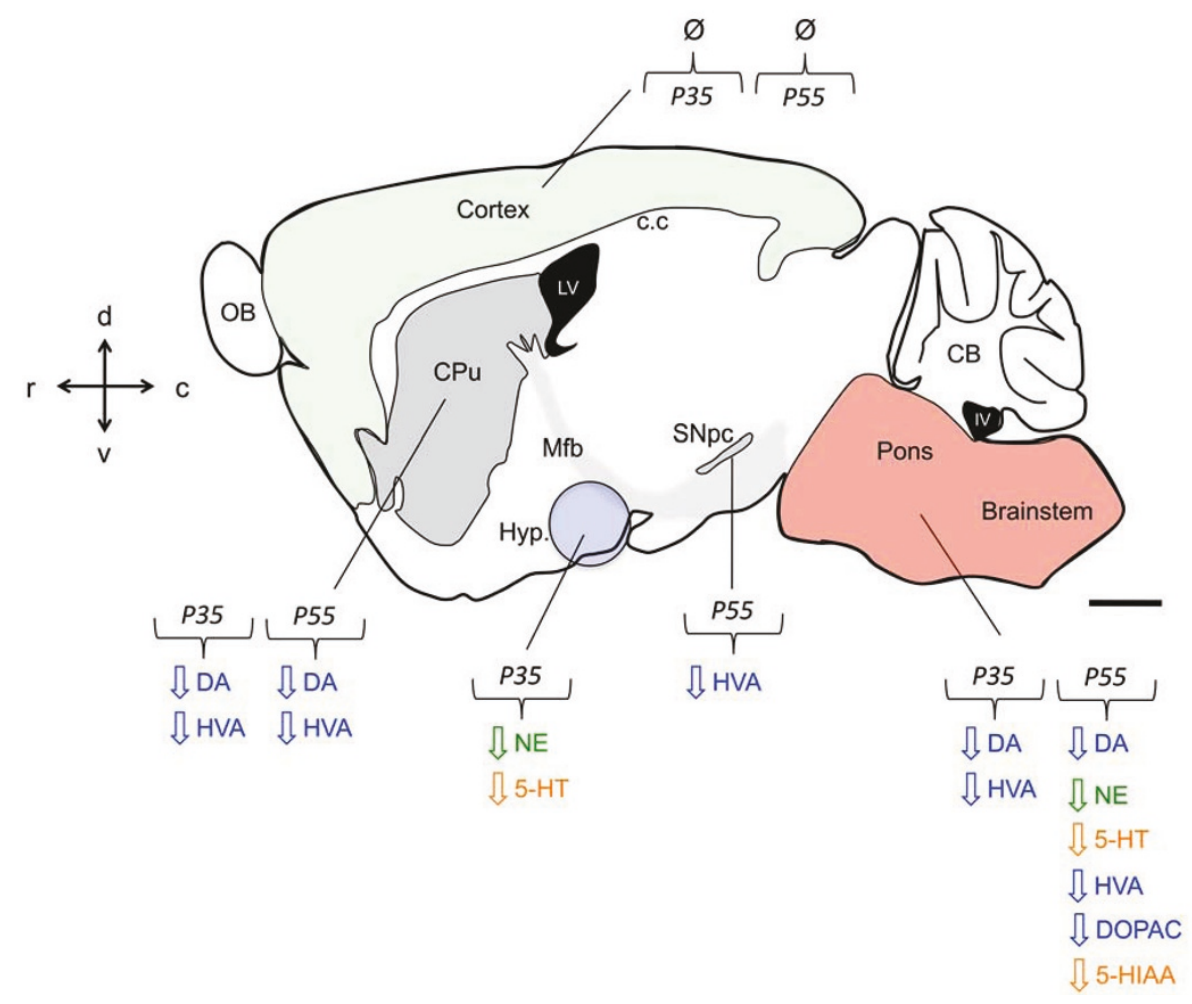

Figure 4 Summary of catecholaminergic \& serotonergic neurochemical measurements in the Mecp $2^{-/ y}$ brain. In mouse, Mecp2 dysfunction leads to the gradual postnatal reduction of dopamine (DA), norepinephrine (NE), serotonin (5-HT) and their principal degradation product dihydroxyphenylacetic acid (DOPAC), homovanillic acid (HVA) and 5-hydroxyindolacetic acid (5-HIAA) in several neuronal populations. These monoaminergic nuclei-related perturbation result in characterized phenotypes that constitute some of the key features of RTT pathology in humans. Sagittal mouse brain drawing adapted from The Mouse Brain in Stereotaxic Coordinates atlas [39]. Area fill in green depict the cortical mantle. In gray the substantia nigra pars compacta (SNpc) irradiating the caudate-putamen (CPu) through the medial forebrain bundle (mfb). Hypothalamic (Hyp) region is symbolized in purple and the pons + brainstem in pink. OB (olfactory bulb), c.c (corpus callosum), CB (cerebellum), LV (lateral ventricle), IV (4 ${ }^{\text {th }}$ ventricle). Scale bar, $1 \mathrm{~mm}$.

filtered with $0.45 \mu \mathrm{m}$ cellulose acetate membranes before use. Elutes were detected at an oxidation potential of $700 \mathrm{mV}$ versus reference electrode. The column and the detection cell were housed within the Faraday cage of the electrochemical detector that was set to $25.5^{\circ} \mathrm{C}$. The day of the analysis, $35 \mu \mathrm{L}$ samples were placed in the autosampler and kept at $+10^{\circ} \mathrm{C}$ before injection. The injection volume was $30 \mu \mathrm{L}$. The retention times were $7 \mathrm{~min}, 11 \mathrm{~min}, 13.5 \mathrm{~min}, 16.5 \mathrm{~min}, 21$ min, 32 min and 42 min for NE, DHBA, DOPAC, DA, 5-HIAA, HVA, and 5-HT, respectively.

\section{Statistical analysis}

We evaluated whether our data distribution fitted with a Gaussian representation using a K-S Kolmogorov-Smirnov Normality test. If valid, data were statistically analyzed using unpaired Student's $t$ test. If not valid, we used an adapted non-parametric Mann-Whitney test to compare genotypes. The results are reported as mean
+/- standard error of the mean (S.E.M). A p-value < 0.05 was considered to be statistically significant.

\section{Acknowledgements}

This study was supported by Inserm, the Provence-Alpes-Côte d'Azur region, AFSR (Association Française du Syndrome de Rett), the E-rare EuroRett network, the Fondation Jérôme Lejeune and the Dischrom project (FP7). Thanks are due to Dr. Sandrine Parrot and Dr. Luc Denoroy from the NeuroChem facility (Université Claude Bernard, Lyon, France) for technical assistance on high performance liquid chromatography.

\section{Author details}

'INSERM UMR_S 910, Unité de Génétique Médicale et Génomique Fonctionnelle, Equipe de Neurogénétique Humaine, France. ${ }^{2}$ Aix-Marseille Université, Faculté de Médecine de La Timone, Marseille, F-13385, France.

\section{Authors' contributions}

LV and JCR conceived and designed the experiment. NP and AG performed the experiments. NP and JCR analyzed the data. NP and JCR wrote the paper. All authors read and approved the final manuscript.

Received: 24 March 2011 Accepted: 24 May 2011

Published: 24 May 2011 


\section{References}

1. Amir RE, Van den Veyver IB, Wan M, Tran CQ, Francke U, Zoghbi HY: Rett syndrome is caused by mutations in X-linked MECP2, encoding methylCpG-binding protein 2. Nat Genet 1999, 23(2):185-188

2. Laurvick CL, de Klerk N, Bower C, Christodoulou J, Ravine D, Ellaway C, Williamson S, Leonard H: Rett syndrome in Australia: a review of the epidemiology. J Pediatr 2006, 148(3):347-352.

3. Chahrour M, Zoghbi HY: The story of Rett syndrome: from clinic to neurobiology. Neuron 2007, 56(3):422-437.

4. Hagberg B, Hanefeld F, Percy A, Skjeldal O: An update on clinically applicable diagnostic criteria in Rett syndrome. Comments to Rett Syndrome Clinical Criteria Consensus Panel Satellite to European Paediatric Neurology Society Meeting, Baden Baden, Germany, 11 September 2001. Eur J Paediatr Neurol 2002, 6(5):293-297.

5. Neul JL, Kaufmann WE, Glaze DG, Christodoulou J, Clarke AJ, BahiBuisson N, Leonard H, Bailey ME, Schanen NC, Zappella M, Renieri A, Huppke P, Percy AK: Rett syndrome: revised diagnostic criteria and nomenclature. Ann Neurol 2010, 68(6):944-950.

6. Ide $S$, Itoh M, Goto $Y$ : Defect in normal developmental increase of the brain biogenic amine concentrations in the mecp2-null mouse. Neurosci Lett 2005, 386(1):14-17.

7. Samaco RC, Mandel-Brehm C, Chao HT, Ward CS, Fyffe-Maricich SL, Ren J, Hyland K, Thaller C, Maricich SM, Humphreys P, Greer J, Percy A, Glaze D, Zoghbi HY, Neul JL: Loss of MeCP2 in aminergic neurons causes cellautonomous defects in neurotransmitter synthesis and specific behavioral abnormalities. Proc Natl Acad Sci USA 2009

8. Roux JC, Villard L: Biogenic Amines in Rett Syndrome: The Usual Suspects. Behav Genet 2009, 40:59-75.

9. Taneja P, Ogier M, Brooks-Harris G, Schmid DA, Katz DM, Nelson SB: Pathophysiology of locus ceruleus neurons in a mouse model of Rett syndrome. J Neurosci 2009, 29(39):12187-12195.

10. Isoda K, Morimoto M, Matsui F, Hasegawa T, Tozawa T, Morioka S, Chiyonobu T, Nishimura A, Yoshimoto K, Hosoi H: Postnatal changes in serotonergic innervation to the hippocampus of methyl-CpG-binding protein 2-null mice. Neuroscience 2010, 165(4):1254-1260.

11. Santos M, Summavielle T, Teixeira-Castro A, Silva-Fernandes A, DuarteSilva S, Marques F, Martins L, Dierssen M, Oliveira P, Sousa N, Maciel P: Monoamine deficits in the brain of methyl-CpG binding protein 2 null mice suggest the involvement of the cerebral cortex in early stages of Rett syndrome. Neuroscience 2010, 170(2):453-467.

12. Panayotis N, Pratte M, Borges-Correia A, Ghata A, Villard L, Roux JC: Morphological and functional alterations in the substantia nigra pars compacta of the Mecp2-null mouse. Neurobiol Dis 2011, 41(2):385-397.

13. Fyffe SL, Neul JL, Samaco RC, Chao HT, Ben-Shachar S, Moretti P, McGill BE, Goulding EH, Sullivan E, Tecott LH, Zoghbi HY: Deletion of Mecp2 in Sim1expressing neurons reveals a critical role for MeCP2 in feeding behavior, aggression, and the response to stress. Neuron 2008, 59(6):947-958.

14. Berridge CW: Neural substrates of psychostimulant-induced arousal. Neuropsychopharmacology 2006, 31(11):2332-2340.

15. Khan AM, Ponzio TA, Sanchez-Watts G, Stanley BG, Hatton GI, Watts AG: Catecholaminergic control of mitogen-activated protein kinase signaling in paraventricular neuroendocrine neurons in vivo and in vitro: a proposed role during glycemic challenges. J Neurosci 2007, 27(27):7344-7360.

16. Rodriguez Fermepin $M$, Trinchero $M$, Minetto J, Beltran A, Fernandez BE: Brain derived neurotrophic factor and neurotrophin-4 employ different intracellular pathways to modulate norepinephrine uptake and release in rat hypothalamus. Neuropeptides 2009, 43(4):275-282.

17. Kutlu S, Aydin M, Alcin E, Ozcan M, Bakos J, Jezova D, Yilmaz B: Leptin modulates noradrenaline release in the paraventricular nucleus and plasma oxytocin levels in female rats: a microdialysis study. Brain Res 2010, 1317:87-91.

18. Dani VS, Chang Q, Maffei A, Turrigiano GG, Jaenisch R, Nelson SB: Reduced cortical activity due to a shift in the balance between excitation and inhibition in a mouse model of Rett syndrome. Proc Natl Acad Sci USA 2005, 102(35):12560-12565.

19. Tropea D, Giacometti E, Wilson NR, Beard C, McCurry C, Fu DD, Flannery R, Jaenisch R, Sur M: Partial reversal of Rett Syndrome-like symptoms in MeCP2 mutant mice. Proc Natl Acad Sci USA 2009, 106(6):2029-2034.
20. Chang Q, Khare G, Dani V, Nelson S, Jaenisch R: The disease progression of Mecp2 mutant mice is affected by the level of BDNF expression. Neuron 2006, 49(3):341-348.

21. Poo MM: Neurotrophins as synaptic modulators. Nat Rev Neurosci 2001, 2(1):24-32.

22. Balkowiec A, Katz DM: Brain-derived neurotrophic factor is required for normal development of the central respiratory rhythm in mice. $J$ Physiol 1998, 510(Pt 2):527-533.

23. Erickson JT, Conover JC, Borday V, Champagnat J, Barbacid M, Yancopoulos G, Katz DM: Mice lacking brain-derived neurotrophic factor exhibit visceral sensory neuron losses distinct from mice lacking NT4 and display a severe developmental deficit in control of breathing. J Neurosci 1996, 16:5361-71.

24. Viemari JC, Roux JC, Tryba AK, Saywell V, Burnet H, Pena F, Zanella S, Bevengut M, Barthelemy-Requin M, Herzing LB, Moncla A, Mancini J, Ramirez JM, Villard L, Hilaire G: Mecp2 deficiency disrupts norepinephrine and respiratory systems in mice. J Neurosci 2005, 25(50):11521-11530.

25. Oo TF, Marchionini DM, Yarygina O, O'Leary PD, Hughes RA, Kholodilov N, Burke RE: Brain-derived neurotrophic factor regulates early postnatal developmental cell death of dopamine neurons of the substantia nigra in vivo. Mol Cell Neurosci 2009, 41(4):440-447.

26. Gu Q: Neuromodulatory transmitter systems in the cortex and their role in cortical plasticity. Neuroscience 2002, 111(4):815-835.

27. Calfa G, Percy AK, Pozzo-Miller L: Experimental models of Rett syndrome based on Mecp2 dysfunction. Exp Biol Med (Maywood) 2011, 236(1):3-19.

28. Yadav VK, Oury F, Suda N, Liu ZW, Gao XB, Confavreux C, Klemenhagen KC, Tanaka KF, Gingrich JA, Guo XE, Tecott LH, Mann JJ, Hen R, Horvath TL, Karsenty G: A serotonin-dependent mechanism explains the leptin regulation of bone mass, appetite, and energy expenditure. Cell 2009, 138(5):976-989.

29. Guy J, Hendrich B, Holmes M, Martin JE, Bird A: A mouse Mecp2-null mutation causes neurological symptoms that mimic Rett syndrome. Nat Genet 2001, 27(3):322-326.

30. Chen RZ, Akbarian S, Tudor M, Jaenisch R: Deficiency of methyl-CpG binding protein-2 in CNS neurons results in a Rett-like phenotype in mice. Nat Genet 2001, 27(3):327-331.

31. Katz DM, Dutschmann M, Ramirez JM, Hilaire G: Breathing disorders in Rett syndrome: progressive neurochemical dysfunction in the respiratory network after birth. Respir Physiol Neurobiol 2009, 168(1-2):101-108.

32. Lioy DT, Wu WW, Bissonnette JM: Autonomic dysfunction with mutations in the gene that encodes methyl-CpG-binding protein 2: Insights into Rett syndrome. Auton Neurosci 2011.

33. Bonham AC: Neurotransmitters in the CNS control of breathing. Respir Physiol 1995, 101(3):219-230.

34. Pratte M, Panayotis N, Gatha A, Villard L, Roux JC: Progressive motor and respiratory metabolism deficits in post-weaning Mecp2-null male mice. Behav Brain Res 2011, 216(1):313-20.

35. Tassin JP: Uncoupling between noradrenergic and serotonergic neurons as a molecular basis of stable changes in behavior induced by repeated drugs of abuse. Biochem Pharmacol 2008, 75(1):85-97.

36. Sara SJ: The locus coeruleus and noradrenergic modulation of cognition. Nat Rev Neurosci 2009, 10(3):211-223.

37. Guevara BH, Torrico F, Hoffmann IS, Cubeddu LX: Lesion of caudateputamen interneurons with kainic acid alters dopamine and serotonin metabolism in the olfactory tubercle of the rat. Cell Mol Neurobiol 2002, 22(5-6):835-844.

38. Youdim MB, Arraf Z: Prevention of MPTP (N-methyl-4-phenyl-1,2,3,6 tetrahydropyridine) dopaminergic neurotoxicity in mice by chronic lithium: involvements of $\mathrm{Bcl}-2$ and Bax. Neuropharmacology 2004, 46(8):1130-1140

39. Paxinos G, Franklin K: The Mouse Brain in Stereotaxic Coordinates. Academic, San Diego; 2001

40. Roux JC, Mamet J, Perrin D, Peyronnet J, Royer C, Cottet-Emard JM, Pequignot JM, Dalmaz Y: Neurochemical development of the brainstem catecholaminergic cell groups in rat. J Neural Transm 2003, 110(1):51-65.

doi:10.1186/1471-2202-12-47

Cite this article as: Panayotis et al: Biogenic amines and their metabolites are differentially affected in the Mecp2-deficient mouse brain. BMC Neuroscience 2011 12:47 